\title{
Geometry and growth of the reconstructed aorta in patients with hypoplastic left heart syndrome and variants
}

\author{
Christoph Haller, MD, ${ }^{\mathrm{a}}$ Devin Chetan, MD,,${ }^{\mathrm{a} b}$ Arezou Saedi, MD, ${ }^{\mathrm{a}}$ Rachel Parker, BScH, ${ }^{\mathrm{a}}$ \\ Glen S. Van Arsdell, MD, ${ }^{\mathrm{a}}$ and Osami Honjo, $\mathrm{MD}, \mathrm{PhD}^{\mathrm{a}}$
}

\section{ABSTRACT}

Objective: The interdigitating technique in aortic arch reconstruction in hypoplastic left heart syndrome and variants (HLHS) reduces the recoarctation rate. Little is known on aortic arch growth characteristics and resulting clinical impact.

Methods: A total of 139 patients with HLHS underwent staged palliation between 2007 and 2014; 73 patients underwent arch reconstruction. Dimensions of ascending aorta, transverse arch, interdigitating anastomosis, and descending aorta in pre-stage II and pre-Fontan angiograms were measured. Aortic arch dimensions were analyzed. Ventricular and atrioventricular valve function were assessed.

Results: Diameters increased in all segments between pre-stage II and pre-Fontan $(P<.0005)$. The $z$ scores remained unchanged in all segments but the descending aorta that was significantly larger pre-Fontan $(P=.039)$. Dimensions and $z$ scores between pre-stage II and pre-Fontan correlated in proximal segments, but not at and distal to the interdigitating anastomosis. Pronounced tapering occurred between the transverse arch and the interdigitating anastomosis. Arch intervention of any type was performed in $7(9.6 \%)$, and intervention for recoarctation in 3 $(4.1 \%)$ patients.

Conclusions: The aortic arch after reconstruction with the interdigitating technique differs from normal. Growth was proportional with no further geometrical distortion. Recoarctation and reintervention rate is low. Further improvement may be achieved by optimizing patch configuration and material. ( $\mathrm{J}$ Thorac Cardiovasc Surg 2017;153:1479-87)

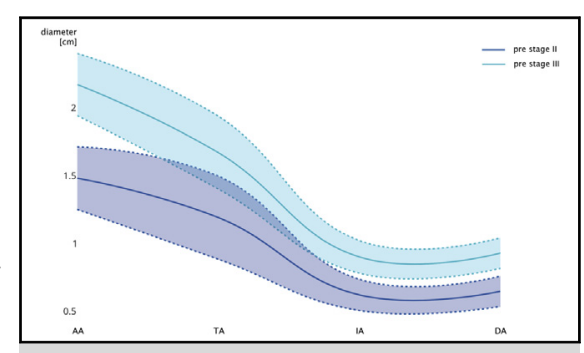

Nonphysiologic aortic geometry and growth after Norwood-type aortic arch repair.

Central Message

The aortic arch after the Norwood operation grows, but its geometry differs significantly from normal and has impact on reinterventions.

\section{Perspective}

Aortic geometry after Norwood arch reconstruction with the interdigitating technique differs from normal. Growth itself is proportional, but the distorted geometry persists. Recoarctation and reintervention rate is low. Reintervention is caused by both deficient and excessive patching. The optimal shape of the neoaorta remains to be further elucidated.

See Editorial Commentary page 1488
Reconstruction of the hypoplastic aortic arch is the most important component of the stage I Norwood procedure in patients with hypoplastic left heart syndrome (HLHS) and variants. Inadequate reconstruction and residual or progressive aortic arch obstruction have been shown to be major risk factors for postoperative morbidity. ${ }^{1}$ Although growth of the neoaorta after the Norwood procedure parallels that of the native aortic arch, its geometry is abnormal and the

\footnotetext{
From the a Division of Cardiovascular Surgery, Hospital for Sick Children, Toronto, Ontario; and ${ }^{\mathrm{b}}$ Department of Pediatrics, University of Alberta, Edmonton, Alberta, Canada.

Received for publication May 6, 2016; revisions received Jan 12, 2017; accepted for publication Feb 4, 2017; available ahead of print March 11, 2017.

Address for reprints: Osami Honjo, MD, PhD, Division of Cardiovascular Surgery, The Hospital for Sick Children, 555 University Ave, Toronto, Ontario, Canada M5G 1X8 (E-mail: osami.honjo@sickkids.ca). $0022-5223 / \$ 36.00$

Copyright (C) 2017 by The American Association for Thoracic Surgery http://dx.doi.org/10.1016/j.jtcvs.2017.02.011
}

biomechanical properties of the aorta are significantly different. $^{2-5}$ This has led to a multitude of different surgical approaches, such as the use of alternative patch materials or the elimination of homologous or xenogenic material. $^{6-10}$ Impaired aortic wall compliance and subsequently increased afterload are related to arch reconstruction and affect right ventricular (RV) function and ventriculoarterial coupling negatively. ${ }^{11}$

Our group and others have shown that the interdigitating technique for aortic arch reconstruction in HLHS and

Scanning this QR code will take you to a supplemental video and figure for the article.

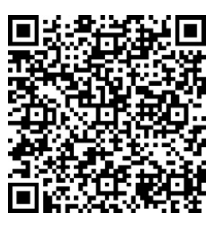




$$
\begin{aligned}
\text { Abbreviations and Acronyms } \\
\text { AA }=\text { ascending aorta } \\
\text { BSA }=\text { body surface area } \\
\text { BT }=\text { Blalock-Taussig } \\
\text { CPB }=\text { cardiopulmonary bypass } \\
\text { CoAI }=\text { coarctation index } \\
\text { DA }=\text { descending aorta } \\
\text { DHCA }=\text { deep hypothermic cardiac arrest } \\
\text { DKS }=\text { Damus-Kaye-Stansel } \\
\text { HLHS }=\text { hypoplastic left heart syndrome } \\
\text { IA }=\text { interdigitating anastomosis } \\
\text { PCPC }=\text { Pediatric Cerebral Performance Category } \\
\text { RV }=\text { right ventricle } \\
\text { SCP }=\text { selective cerebral perfusion } \\
\text { TA }=\text { transverse arch }
\end{aligned}
$$

variants is associated with much lower incidence of recoarctation before stage II palliation. ${ }^{12,13}$ No study has been performed to investigate the effects of the interdigitating technique on late recoarctation and aortic arch geometry and growth beyond the infantile period. We hypothesized that the low incidence of recoarctation with the interdigitating technique persists during follow-up and that it reflects in changes in aortic arch geometry and growth patterns.

\section{MATERIALS AND METHODS}

A retrospective chart review of all patients with HLHS and variants undergoing a Norwood-type arch reconstruction between 2007 and 2014 at the Hospital for Sick Children, Toronto, was performed. Institutional review board approval was obtained and patient consent was waived. Patients with a hybrid palliation strategy (ie, initial bilateral pulmonary artery banding with or without ductal stenting, followed by a comprehensive stage I+II procedure) were excluded from the study. Baseline population data, surgical details, postoperative and interstage complications, and clinical events, including reinterventions, death from any causes, and transplantation were collected. A total of 139 patients with HLHS and variants were palliated during the study period; 73 patients underwent stage I Norwood-type single-ventricle palliation. Pre-stage II and pre-Fontan angiography was performed in $52(71.2 \%)$ and $21(28.8 \%)$ patients, respectively. Patient profiles are shown in Table 1, operative details are summarized in Table 2.

\section{Surgical Technique}

The Norwood procedure comprised aortic arch reconstruction, atrial

\begin{tabular}{|c|c|c|c|}
\hline & $\begin{array}{l}\text { Total, } \\
\text { n }(\%)\end{array}$ & $\begin{array}{c}\text { Pre-stage II, } \\
\text { n }(\%)\end{array}$ & $\begin{array}{c}\text { Pre-Fontan, } \\
\text { n }(\%) \\
\end{array}$ \\
\hline Number of patients & $73(100)$ & $52(100)$ & $21(100)$ \\
\hline Male & $44(60.3)$ & $34(65.4)$ & $16(76.2)$ \\
\hline Prematurity & $15(20.5)$ & $11(21.2)$ & $4(19.0)$ \\
\hline \multicolumn{4}{|l|}{ Diagnosis } \\
\hline HLHS & $43(58.9)$ & $27(51.9)$ & $9(42.9)$ \\
\hline TGA/ccTGA & $14(19.2)$ & $13(25.0)$ & $8(38.1)$ \\
\hline Tricuspid atresia & $7(9.6)$ & $7(13.5)$ & $3(14.3)$ \\
\hline DORV & $4(5.5)$ & $4(7.7)$ & $0(0.0)$ \\
\hline AVSD & $3(4.1)$ & $0(0.0)$ & $0(0.0)$ \\
\hline other & $2(2.7)$ & $1(1.9)$ & $1(4.8)$ \\
\hline \multicolumn{4}{|l|}{ Shunt } \\
\hline Modified BT-Shunt & $65(89.0)$ & $46(88.5)$ & $20(95.2)$ \\
\hline \multirow[t]{2}{*}{ Sano shunt } & $8(11.0)$ & $6(11.5)$ & $1(4.8)$ \\
\hline & Baseline & $\begin{array}{c}\text { Pre-stage II } \\
\text { Mean }( \pm \text { SD) }\end{array}$ & $\begin{array}{c}\text { Pre-Fontan } \\
\text { Mean }( \pm \text { SD) } \\
\end{array}$ \\
\hline \multicolumn{4}{|l|}{ Baseline parameters } \\
\hline Age, y & $\mathrm{n} / \mathrm{a}$ & $0.36 \pm 0.09$ & $2.39 \pm 0.44$ \\
\hline BSA, $\mathrm{m}^{2}$ & $\mathrm{n} / \mathrm{a}$ & $0.29 \pm 0.04$ & $0.56 \pm 0.05$ \\
\hline \multicolumn{4}{|c|}{ Echocardiography, median (IQR) } \\
\hline Ventricular function & $0.0(0.0-0.0)$ & $0.0(0.0-0.0)$ & $0.0(0.0-0.0)$ \\
\hline AV-valve function & $0.0(0.0-1.0)$ & $1.0(0.0-1.5)$ & $0.25(0.0-1.0)$ \\
\hline Follow-up, y & $2.17 \pm 2.13$ & $2.39 \pm 2.04$ & $2.03 \pm 1.96$ \\
\hline
\end{tabular}
septectomy, and construction of either a modified Blalock-Taussig (BT) or a Sano shunt, respectively. Choice of palliation strategy was made in a multidisciplinary meeting including opinions from surgeons, cardiologists, and family. Since 2012, we switched to a protocol-based approach in which patients with a body weight less than $2.0 \mathrm{~kg}$ were triaged to a hybrid strategy and any other patient underwent a Norwood procedure. Hemodynamically unstable patients or patients unsuitable for major cardiac surgery (eg, cerebral bleed) underwent salvage hybrid palliation and were excluded from the analysis. Deep hypothermic cardiac arrest (DHCA) with selective cerebral perfusion (SCP) was used during arch reconstruction. The interdigitating technique has been described previously. ${ }^{12}$ In short, a complete coarctectomy with extended anastomosis of the distal aortic arch with the posterolateral wall of the descending aorta is performed, followed by an
TABLE 1. Baseline, pre-stage II, and pre-stage III patient profiles

HLHS, Hypoplastic left heat syndrome; TGA, transposition of the great arteries; $c c T G A$, congenitally corrected transposition of the great arteries; DORV, double outlet right ventricle; $A V S D$, atrioventricular septal defect; $B T$, Blalock-Taussig; $S D$, standard deviation; $n / a$, not applicable; $B S A$, body surface area; $I Q R$, interquartile range; $A V$, atrioventricular.

anterolateral counter incision. The aortic arch is then augmented with a homograft patch. Pulmonary homograft was used as patch material in all patients. This creates a distal suture line that extends beyond the circumference of the descending aorta in its anterior and posterior aspect. As opposed to mere enlargement of an area of potential residual ductal tissue, the interdigitating anastomosis of native arch to native descending aortic tissue allows for better growth and less restriction. In case of anterior patch enlargement beyond the isthmic region alone, there is a potential for residual circumferential ductal tissue in the native descending aorta that can cause narrowing with time as the patch itself does not contribute to growth. Patients with transposed great vessels commonly had a doublebarrel modification of the Damus-Kaye-Stansel (DKS) anastomosis.

Stage II palliation was performed at the age of 5 to 6 months. A bidirectional cavopulmonary shunt was constructed on cardiopulmonary bypass (CPB) with mild hypothermia. Routine bilateral pulmonary artery patching was performed to avoid any impairment of pulmonary blood flow, especially at the area of the former shunt insertion. The extent of peripheral branch pulmonary artery patching was based on the individual anatomy. Aortic cross clamping and cardioplegic arrest was used only if additional intracardiac procedures had to be performed. Fontan completion was performed at approximately 2.5 to 3 years of age. Fontan operation was performed on normothermic CPB with an extracardiac fenestrated conduit. Unless concomitant intracardiac procedures were necessary, no aortic cross clamping and cardioplegic arrest were used.

\section{Aortic Arch Measurements}

Aortic arch dimensions were assessed on pre-stage II and pre-Fontan angiograms. Measurements were performed by a trained single observer at a Syngo Dynamics Workstation (Siemens Health Care GmbH, Erlangen, 
TABLE 2. Operative details

\begin{tabular}{|c|c|c|c|}
\hline & $\begin{array}{c}\text { Stage I, } \\
\text { n (\%) }\end{array}$ & $\begin{array}{c}\text { Stage II, } \\
\text { n (\%) }\end{array}$ & $\begin{array}{c}\text { Stage III, } \\
\text { n ( } \%)\end{array}$ \\
\hline Number of patients & $73(100)$ & $51(100)$ & $20(100)$ \\
\hline Male & $44(60.3)$ & $34(66.6)$ & $15(75.0)$ \\
\hline Prematurity & $15(20.5)$ & $11(21.6)$ & $4(20.0)$ \\
\hline \multicolumn{4}{|c|}{ Intraoperative, mean $\pm \mathrm{SD}$} \\
\hline Age, y & $0.08 \pm 0.39$ & $0.49 \pm 0.20$ & $2.4 \pm 0.99$ \\
\hline Body weight, $\mathrm{kg}$ & $3.48 \pm 1.09$ & $6.38 \pm 1.40$ & $12.63 \pm 3.52$ \\
\hline $\mathrm{BSA}, \mathrm{m}^{2}$ & $0.23 \pm 0.04$ & $0.36 \pm 0.05$ & $0.52 \pm 0.09$ \\
\hline $\mathrm{CPB}, \min$ & $128.67 \pm 68.74$ & $96.32 \pm 54.30$ & $56.40 \pm 40.99$ \\
\hline $\mathrm{X}$-clamp, min & $66.71 \pm 27.36$ & $26.96 \pm 51.89$ & $12.80 \pm 40.98$ \\
\hline DHCA, min & $20.00 \pm 15.71$ & $3.48 \pm 12.61$ & $3.28 \pm 12.05$ \\
\hline $\mathrm{SCP}, \min$ & $39.59 \pm 21.23$ & $1.11 \pm 7.45$ & $0.00 \pm 0.00$ \\
\hline \multicolumn{4}{|c|}{ Postoperative, median (IQR) } \\
\hline Intubation, d & $10.0(6.0-13.3)$ & $1.0(0.0-3-0)$ & $0.0(0.0-0.0)$ \\
\hline ICU stay, d & $15.0(11.8-27.5)$ & $4.0(1.0-6.0)$ & $1.0(1.0-3.0)$ \\
\hline Hospital stay, d & $30.0(19.5-58.0)$ & $9.0(6.0-14.0)$ & $10.5(7.0-15.3)$ \\
\hline \multicolumn{4}{|l|}{ Echocardiography } \\
\hline Ventricular function & $0.0(0.0-0.0)$ & $0.0(0.0-0.0)$ & $0.0(0.0-0.0)$ \\
\hline AV-Valve function & $1.0(0.0-1.5)$ & $1.0(0.0-1.25)$ & $0.0(0.0-1.5)$ \\
\hline
\end{tabular}

Germany). Left anterior oblique angiograms perpendicular to the anteroposterior orientation of the aortic arch were chosen. Still images were captured at the maximal systolic distension of the ascending aorta. Dimensions were measured perpendicularly to the vessel's longitudinal axis.

Arch dimensions were measured at 4 predefined locations (Figure 1 and Video 1):

- Ascending aorta (AA)

Diameter directly superior to the DKS anastomosis.

- Transverse arch (TA)

Diameter at the take-off of the brachiocephalic trunk and the left common carotid artery. If variations of the supraaortic vessels were present, TA was defined as the take-off of the first supraaortic vessel.

- Interdigitating anastomosis (IA)

Narrowest diameter distal of the supraaortic vessel that originates most distally from the aortic arch.

- Descending aorta (DA)

Diameter of the supradiaphragmatic aorta.

$Z$ scores were calculated based on our institution-specific patient population. Intersegmental ratios can be considered as abstractions of coarctation index $(\mathrm{CoAI})$, which is used to grade the severity of distal arch obstruction in magnetic resonance images by division of isthmic crosssectional area by descending aortic cross-sectional area at the diaphragmatic level. ${ }^{14}$ These ratios were calculated as AA/TA, TA/IA, and IA/DA and reflect the grade of diameter reduction. Accordingly, we refer to IA/ DA as CoAI. Although ratios need to be interpreted carefully, they add depth to the description of aortic geometry as they reflect diameter reduction within a segment and may help interpret irregularities of the aortic arch tapering. The lower the ratio, the more important the increase in diameter across the segment and vice versa. The gradual reduction in diameter from proximal to distal aorta, described as aortic tapering, was assessed by the difference between $\mathrm{AA}$ and DA dimensions and $z$ scores and the relative increase or reduction between the segments.

\section{Reintervention and Recoarctation}

We did not use a certain gradient as a sole indicator for reintervention. Especially in the presence of an aortopulmonary shunt, gradients may not be reliable. On the other hand, measurements of CoAI did not differ in those who had reinterventions for recoarctation. Therefore, decisions were based on a combination of clinical status, ventricular function, gradients, and anatomical obstruction or narrowing.

\section{Statistical Analysis}

Descriptive analysis is presented as frequency (percent) for nominal or categorical variables and mean \pm standard deviation for interval or continuous data. Statistical significance was set to $P \leq .05$. Differences between groups were assessed with the Student $t$ test for normally distributed variables. Within group analysis was performed with the paired $t$ test. One-sample $t$ test was used to calculate significant difference between mean $z$ scores and 0. Correlation of variables was calculated using Spearman or Pearson correlation for continuous or interval data, respectively. Statistical analysis was performed using SAS Studio, University Edition (SAS Institute Inc, Cary, NC), IBM SPSS 23.0 (IBM Corporation, Armonk, NY), and RStudio 0.99.902 (RStudio, Inc, Boston, Mass).

\section{RESULTS \\ Patient Population}

Male sex was more common; $20.5 \%$ of patients were premature with a gestational age $\leq 37$ weeks. The most common diagnosis was HLHS, followed by transpositiontype malformations, tricuspid atresia, double outlet right ventricle, unbalanced atrioventricular septal defect, and other variants. Details are depicted in Tables 1 and 2. Inhospital mortality after stage I was $13.7 \%$. Interstage mortality was $11.1 \%$. There were 18 patients with double-barrel configuration of the DKS anastomosis, 55 patients had a conventional DKS as part of their Norwood procedure.

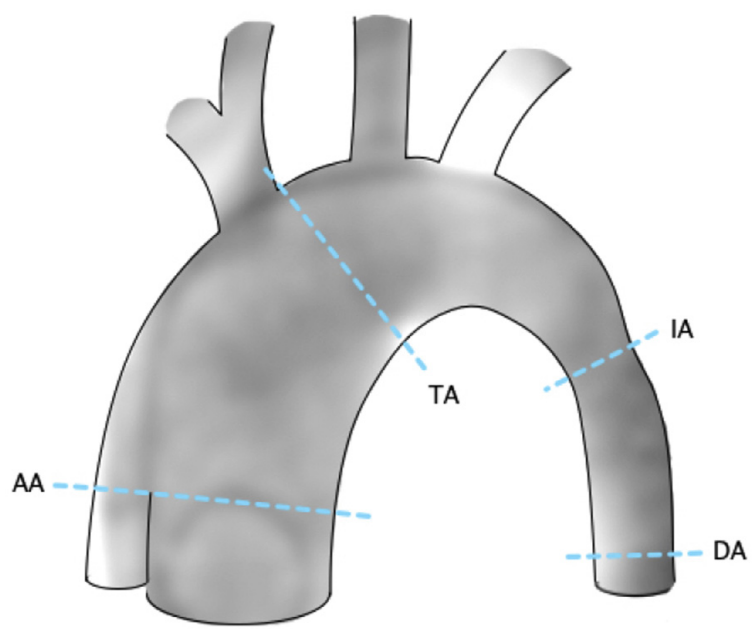

FIGURE 1. Points of measurement on lateral angiograms. $A A$, Ascending aorta; $T A$, transverse arch; $I A$, interdigitating anastomosis; $D A$, descending aorta. 


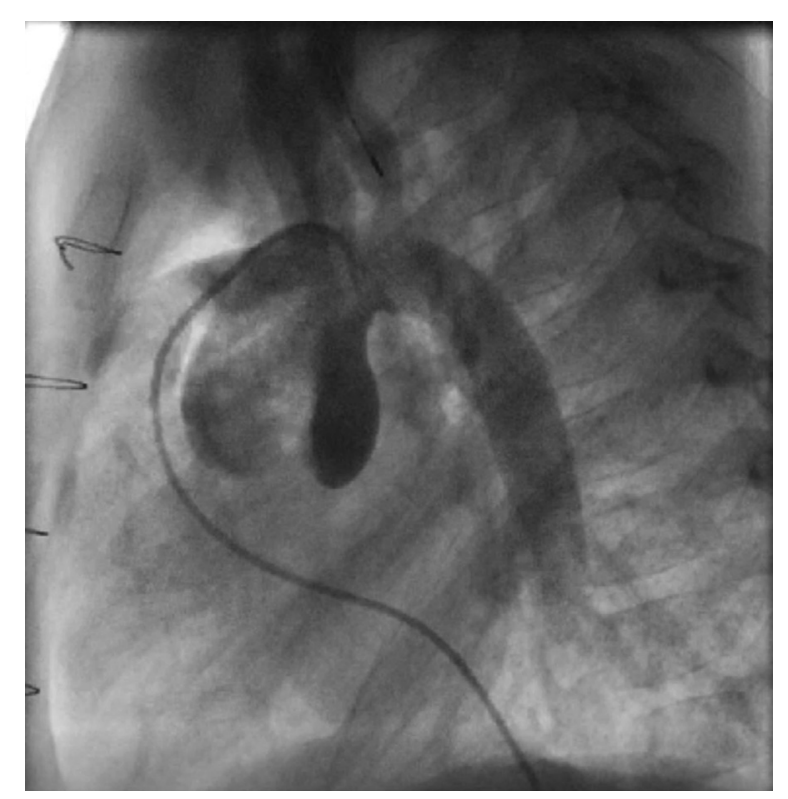

VIDEO 1. Aortic arch angiography and aortic arch measurements. Video available at: http://www.jtcvsonline.org/article/S0022-5223(17)30222-2/ addons.

\section{Pre-Stage II Aortic Arch Dimensions}

Dimensions at AA and TA were larger than the normed diameters for the respective body surface area (BSA). In contrast, diameters measured at IA and DA were similar to those expected for the respective BSA (Figures 2 and 3). $Z$ score analysis showed significantly higher than normal $z$ scores at AA $(5.31 \pm 1.51, P<.0005)$ and TA $(4.45 \pm 2.47, P<.0005)$, and significantly lower $z$ scores at IA $(-0.54 \pm 1.61, P=.030)$ and DA $(-0.72 \pm 1.52$, $P=.002$ ) (Figure 4).

Assessment of intersegmental differences in aortic diameters revealed significant reductions from AA to TA $(P=.022)$ and TA to IA $(P<.0005)$, but not from IA to DA $(P=.551)$. The greatest reduction in mean aortic diameter occurred between TA and IA, contributing to $67.3 \%$ of the overall tapering, corresponding to a mean $z$ score reduction of 4.99 (82.8\% reduction in $z$ score) (Figure E1).

\section{Pre-Fontan Aortic Arch Dimensions}

The larger dimensions compared with normed diameters for respective BSA at AA and TA persisted on pre-Fontan angiograms (Figures 2 and 3). Diameters measured at IA and DA again equaled those expected for the respective BSA. Accordingly, $z$ score analysis showed significantly higher than normal $z$ scores at AA (5.99 \pm 0.99 , $P<.0005)$ and TA $(4.82 \pm 1.51, P<.0005)$, but normal $z$ scores at IA $(0.20 \pm 1.11, P=.448)$ and DA $(0.10 \pm 1.13, P=.702)$ (Figure 4).

Intersegmental differences in aortic diameters revealed significant reductions from AA to TA $(P=.008)$ and TA to IA $(P<.0005)$, but not from IA to DA $(P=.676)$. Again, the mean aortic diameter narrowed predominantly between TA and IA, $61.1 \%$ of the overall tapering, corresponding to a mean $z$ score reduction of $4.62(78.4 \%$ reduction in $z$ score) (Figure E1).

\section{Pre-Stage II to Pre-Stage III Geometry and Growth}

Absolute diameters changed significantly in all segments between pre-stage II and pre-Fontan $(P<.0005)$. Mean changes in aortic dimensions paralleled the increase of arch dimensions normed to BSA (Figures 2 and 3). $Z$ scores showed no significant change between pre-stage II and preFontan measurements at AA $(P=.931)$, TA $(P=.425)$, and IA $(P=.121)$. There was a small but significant increase in DA $z$ scores $(P=.039)$.

Intersegmental ratios in aortic diameters remained unchanged in the AA-TA (pre-stage II $1.34 \pm 0.28 \mathrm{~mm}$ vs pre-Fontan $1.32 \pm 0.23 \mathrm{~mm}, P=.784$ ), TA-IA (pre-stage II $2.02 \pm 0.56 \mathrm{~mm}$ vs pre-Fontan $1.89 \pm 0.49 \mathrm{~mm}$, $P=.221$ ), and the IA-DA (pre-stage II $0.95 \pm 0.12 \mathrm{~mm}$ vs pre-Fontan $0.96 \pm 0.11 \mathrm{~mm}, P=.757$ ) segment. Intersegmental $z$ score ratios showed a trend to smaller ratios in the TA-IA segment only (pre-stage II $5.94 \pm 22.54$ vs pre-Fontan $-8.30 \pm 22.00, P=.067$ ), but not between AA and TA (pre-stage II $1.52 \pm 0.74$ vs pre-Fontan $1.35 \pm 0.47, P=.360$ ) or IA and DA (pre-stage II $0.07 \pm 1.67$ vs pre-Fontan $2.54 \pm 6.31, P=.114$ ) (Figures 4 and 5).

\section{HLHS Subgroup Analysis}

When compared with patients without HLHS, those with isolated HLHS neither showed a significant difference in absolute nor $z$ score measurements on pre-stage II angiography. Absolute and $z$ score values were significantly larger at TA in patients with HLHS before stage III $(P=.016 /$ .018). Analysis of growth between pre-stage II and prestage III revealed that absolute dimensions increased significantly at all points of measurements in both HLHS and variant patients. However, $z$ scores remained the same in all segments of patients with HLHS, whereas the variant group showed a trend to larger IA $z$ scores $(P=.060)$ and significantly larger DA $z$ scores $(P=.031)$ on pre-stage III angiography.

\section{Reintervention and Recoarctation}

Arch intervention of any type was performed in $7(9.6 \%)$ patients. Freedom from reintervention from any cause was $87.3 \%$ after a maximal follow-up of 7.28 years; 4 (5.5\%) patients needed reintervention for excessive arch dimensions (intraluminal fold of the patch, vascular compression of adjacent bronchi or pulmonary arteries, patch-induced kinking of supraaortic branches) and $3(4.1 \%)$ patients were treated for recoarctation. Only $1(1.4 \%)$ patient treated for recoarctation had a coarctation index less than 0.7. Freedom from recoarctation was $95.5 \%$ (Figure 5). 


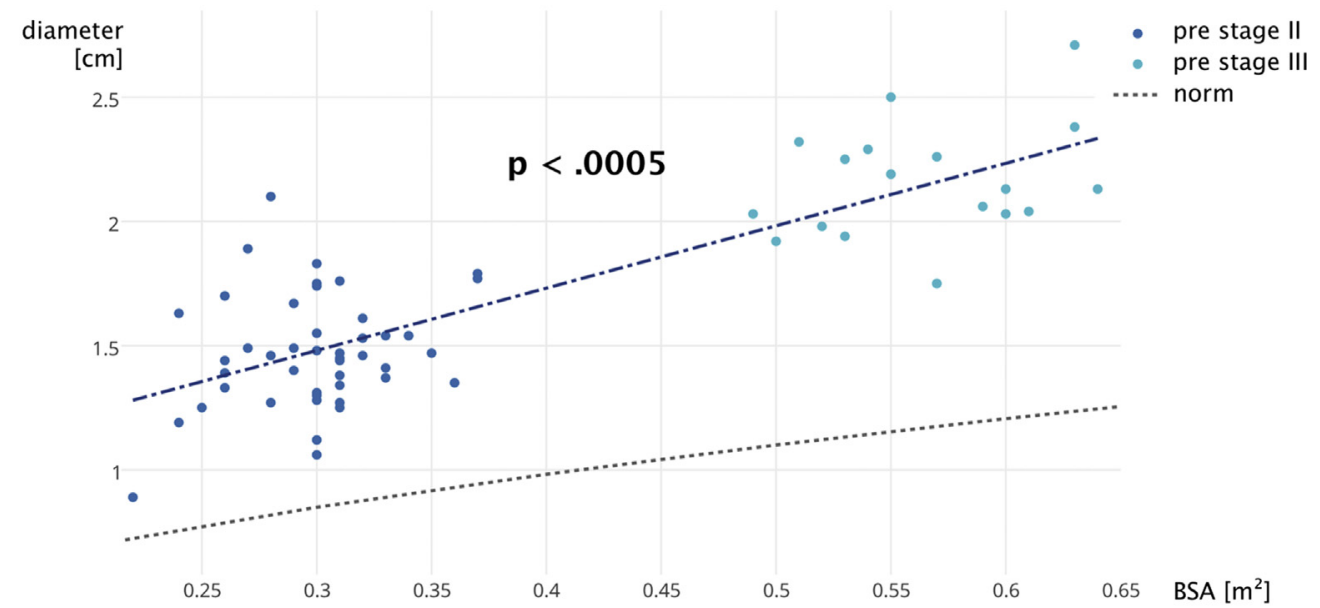

A

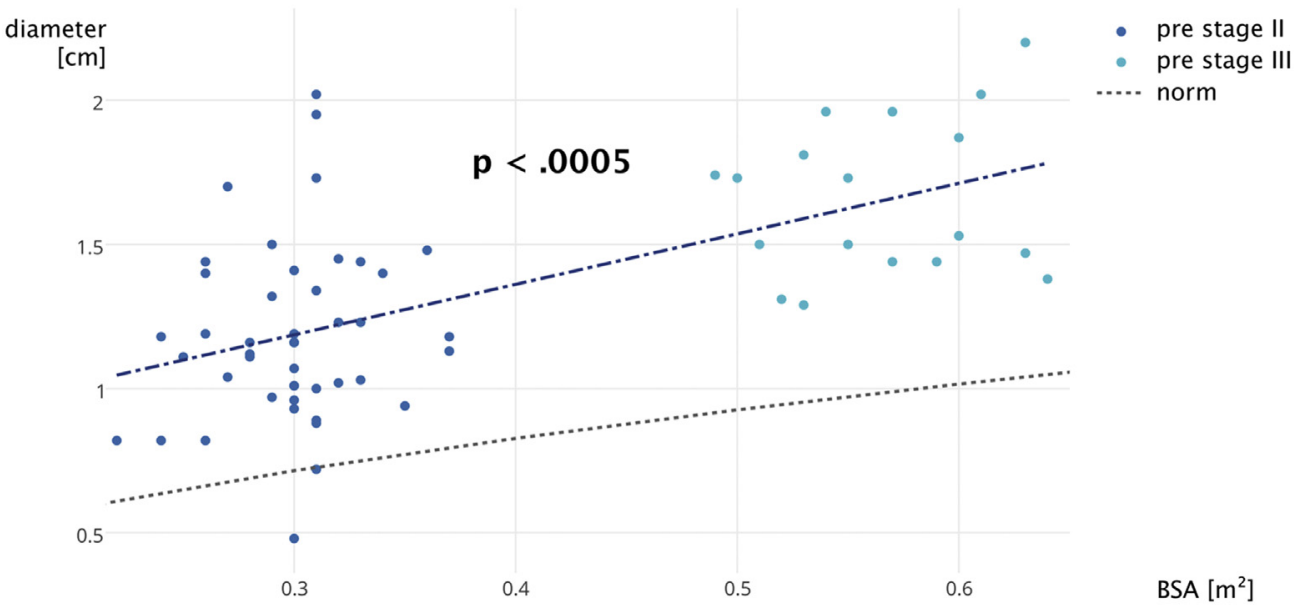

B

FIGURE 2. Dimensions of ascending aorta and transverse arch versus body surface area (BSA) at pre-stage II and pre-Fontan. A, Ascending aorta. B, Transverse arch. Grey dotted line (norm) depicts $z$ score of 0 at respective body surface area (BSA).

Of patients dying in hospital after stage I, $7(9.6 \%)$ had a reintervention of any type, $3(4.1 \%)$ for recoarctation, 4 $(5.5 \%)$ for excessive patch enlargement.

\section{DISCUSSION}

Early outcome of the Norwood procedure has substantially improved, with experienced centers achieving inhospital survival rates of up to $93 \% .{ }^{15}$ Attention has therefore shifted toward reduction of interstage morbidity and mortality, better neurodevelopment, and improvement of long-term outcome in general. ${ }^{16,17}$

The reconstruction of the hypoplastic aorta and especially aortic obstruction have been identified as factors that influence outcome significantly. ${ }^{1,4}$ A multitude of variations have therefore been developed to ensure adequate enlargement of the aorta and to reduce the rate of recoarctation. ${ }^{7,8,12,13,18}$ The interdigitating technique addresses the potential risk of circumferential narrowing at the level of the distal anastomosis by residual ductal tissue. $^{12,19,20}$ To achieve unobstructed blood flow, wide angles and dimensions are sought. This can influence blood flow within the aorta beneficially. ${ }^{21}$ But there is more to the reconstructed aortic arch than just distal narrowing. Impaired ventriculoarterial coupling, reduced wall elasticity, and the interaction among geometry, elasticity, and ventricular function have been shown and emphasized. . $^{2,21,22}$ We hypothesized that the geometry of the aortic arch differs substantially from that of the normal aorta and that this alteration influences outcome. We also investigated how the geometry changed during follow-up. Finally, we hypothesized that the incidence of recoarctation can be minimized with an interdigitating reconstruction.

In summary, the geometry of the neoaortic arch is significantly altered. This abnormal geometry shows no restriction of growth in general, but persists during follow-up. Recoarctation rate is low and interventions are triggered as commonly by proximal arch pathology. 

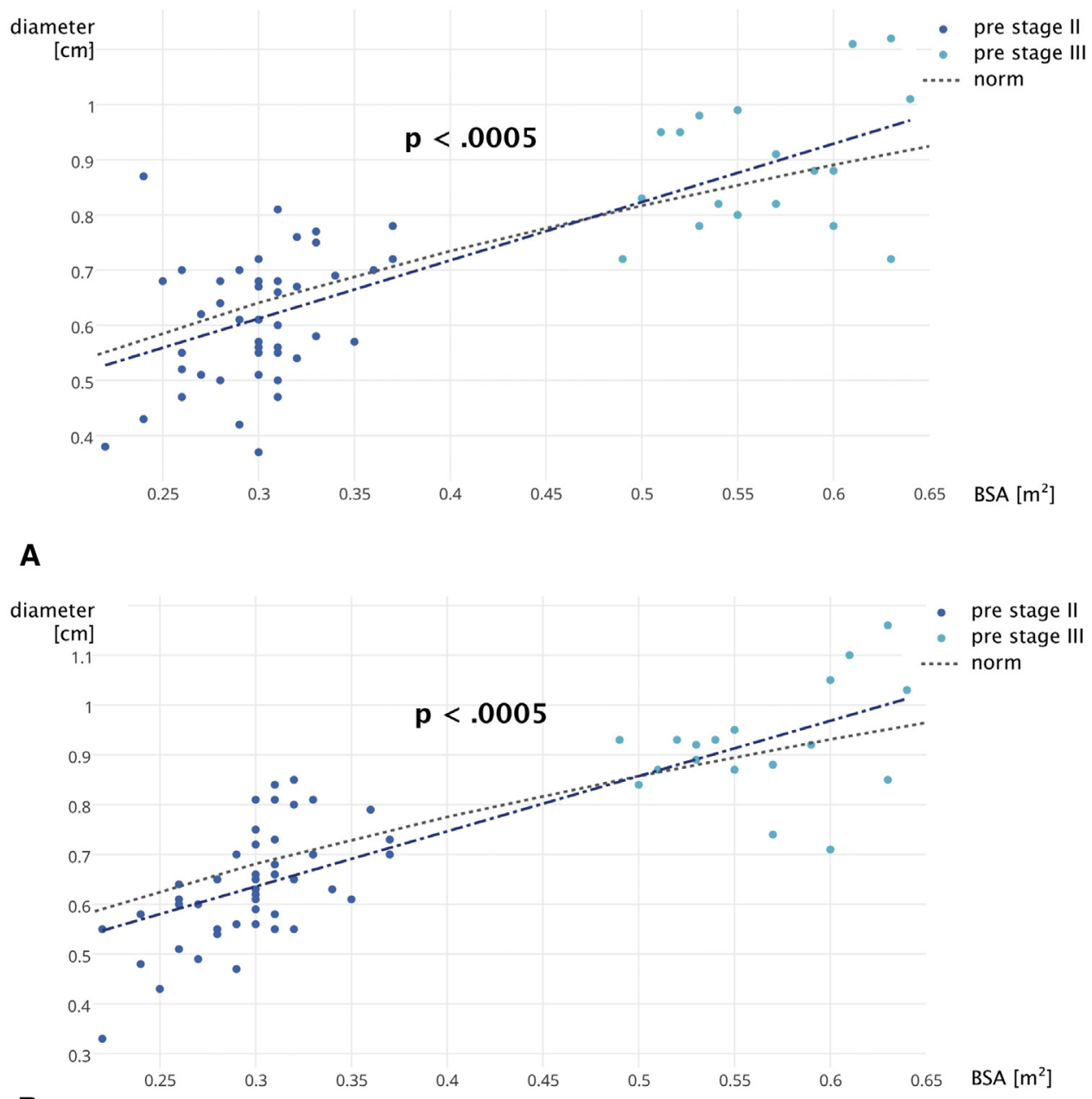

B

FIGURE 3. Dimensions of interdigitating anastomosis and descending aorta versus body surface area (BSA) at pre-stage II and pre-Fontan. A, Interdigitating anastomosis. B, Descending aorta. Grey dotted line (norm) depicts $z$ score of 0 at respective BSA.

\section{Pre-Stage II Arch Dimensions}

Measurements of AA and TA were substantially larger than the expected arch dimension for a patient with the same BSA. The discrepancy at the level of AA can be explained by the proximity of the DKS anastomosis and the size of the pulmonary trunk, which is usually much larger in patients with a hypoplastic aorta. Furthermore, the necessarily higher cardiac output in the setting of a modified BTshunt necessitates a larger conduit.

Dimensions of the isthmic region and the DA approached normal values when considering the respective BSA. The marked difference between absolute diameters and $z$ scores of the proximal (AA and TA) and the distal aorta (IA and DA) reflects the unnatural geometry of the reconstructed aorta. Although the measurements were not continuous, a relatively sudden narrowing between the distal aortic arch and the isthmic region can be appreciated, without evidence of a localized isthmic narrowing (ie, recoarctation).
Intersegmental difference between IA and DA, which commonly determines the presence or absence of coarctation and may be regarded as one of the key aspects of the reconstruction, showed no significant difference in diameter. This is even more striking considering the sometimes very localized (pre-isthmic) change in diameter noted on angiography.

\section{Pre-Fontan Arch Dimensions}

The discrepancy between proximal and distal aortic dimensions and $z$ scores, as well as the intersegmental differences between AA and TA, TA and IA, or IA and DA found at pre-stage II persisted at pre-Fontan. The decrease of aortic diameter was again most pronounced between TA and IA. The lack of significant difference between IA and DA illustrates that recoarctation in the setting of an interdigitating arch reconstruction is prevented effectively and that there is no delayed growth restriction in the isthmic region. 


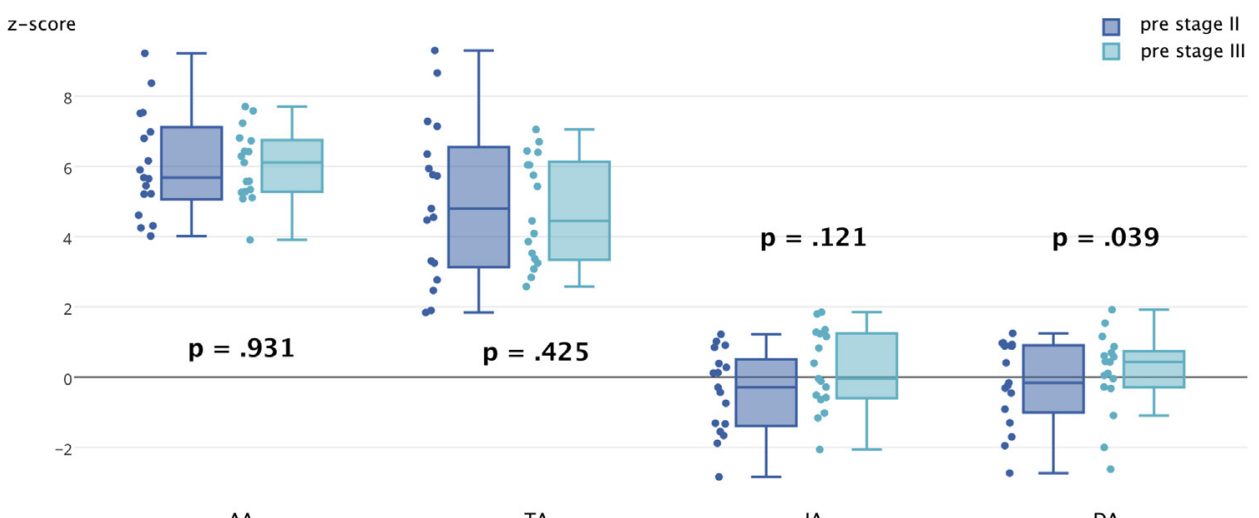

AA

TA

IA

DA

FIGURE 4. The $z$ scores and their interstage differences. $A A$, Ascending aorta; $T A$, transverse arch; $I A$, interdigitating anastomosis; $D A$, descending aorta.

\section{Pre-Stage II to Pre-Stage III Geometry and Growth}

Growth between pre-stage II and pre-Fontan was unimpaired in all segments. Especially with regard to the potential risk of recoarctation, the growth of the isthmic region appears to be as gradual as that of the healthy population. On the other hand, growth characteristics of DA may challenge the completely unimpaired growth of the IA. As we interpret the small but significant increase in DA $z$ scores at pre-Fontan as an effect of increased lower body perfusion after take-down of the systemic to pulmonary artery shunt at stage II, an increased diameter could also be expected at IA. The lack of significantly higher IA $z$ scores at pre-Fontan may indicate that despite the low recoarctation rate using the presented technique, a subclinical residual growth restriction at the distal anastomosis of the arch reconstruction remains.

Although no significant difference could be found between the $z$ scores at pre-stage II and pre-Fontan for AA, TA, and IA, as well as for the intersegmental differences, direct comparison of absolute diameters, as is shown in Figure E1, can be interpreted as the result of intrinsic, but insufficient adjustment toward a more gradual tapering. Unfortunately, pathologic examination or diagnostic imaging was not available, to further delineate if growth occurred predominantly in native tissue. Nevertheless, there is evidence in the literature that growth restriction of the patch is compensated by native tissue and that the patch material does not contribute to the increase of the aortic size. ${ }^{23}$ According to our analysis, $z$ scores do not decrease with time, indicating that the native aortic wall can enlarge substantially. We may not be able to answer whether current techniques of aortic arch reconstruction tend to overcompensate, but considering the incidence of aortic arch revision caused by excessive patch dimensions, overcompensation can be as harmful as insufficient patching.

We lack a clear explanation for the differences between patients with HLHS and patients with variants thereof. If the increase in DA dimensions is indeed an effect of increased lower body perfusion after removal of the shunt, the fact that it is predominantly seen in patients with HLHS variants may suggest that the isthmic region and the distal aorta in patients with HLHS is less plastic with regard to its growth potential.

\section{Reintervention and Recoarctation}

The incidence of arch reintervention of any type was very low. The exceptionally low recoarctation rate of $4.1 \%$ is similar to the results shown after shorter follow-up ${ }^{12,13,24}$ and emphasizes both the effectiveness of the interdigitating technique and the longevity of this type of repair with regard to the distal anastomosis. It has been previously shown that recoarctation is caused by residual ductal tissue and insufficient distal patch augmentation. ${ }^{20}$ Recoarctation has also been associated with deterioration of ventricular function. ${ }^{1}$ In our analysis, interventions needed to be performed even more often for excessive arch dimensions then for coarctation. Again, creation of wide, nonanatomical dimensions leads to impaired outcome. Avoiding the risk of obstruction by excessive patching comes with a higher risk of complications due to kinking or external compression of adjacent structures and cannot be advised unequivocally. This compromising effect has been highlighted by Hasegawa et $\mathrm{al}^{24}$ recently, as they showed the importance of adequate aortopulmonary space to reduce reintervention rates. Achieving adequate but not excessive patching in each patient is challenging, and there is not a standard technique available that can guarantee success. ${ }^{12,25}$ Upcoming techniques for 3-dimensional tissue grafts could be used to help the surgeon to achieve uniform tapering and undistorted geometry.

A censoring effect of patients with aortic arch obstruction who did not reach either pre-stage II or pre-Fontan angiography can most likely be excluded, as patient charts were screened for arch complications necessitating intervention 

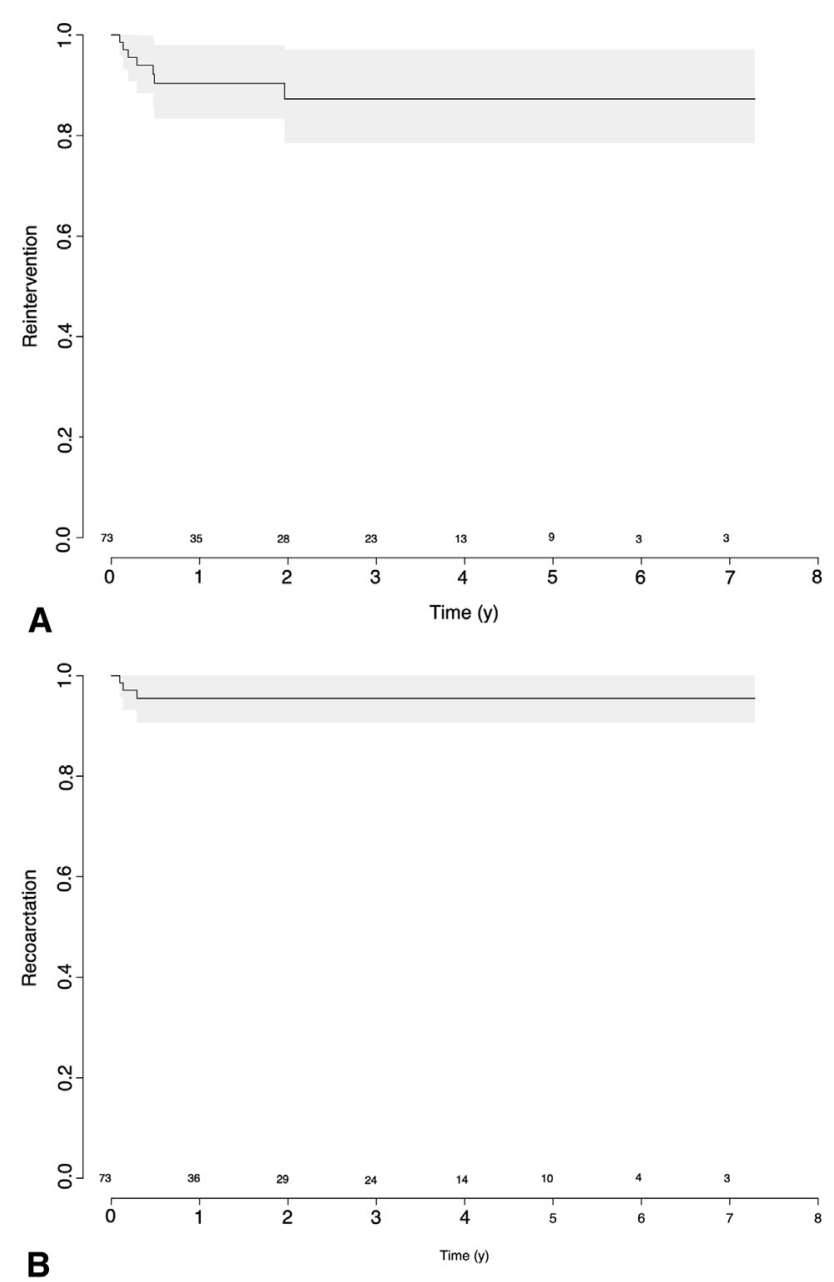

FIGURE 5. Freedom from any reintervention or reintervention for recoarctation. A, Freedom from any reintervention. B, Freedom from recoarctation.

irrespective of angiographic proof. The remaining limitation refers to outpatients with an unclear mode of death. Unfortunately, a more detailed analysis of the arch morphology in patients who failed to progress to subsequent stages is limited by the lack of angiographic data in most of these patients. Nevertheless, it is important to note that the lower number of patients at later stages is not related to mortality alone, as a relevant number of patients may not have completed all 3 stages within the study period.

\section{Study Limitations}

The study results are limited by the diversity of the underlying patient population and the decreasing number of patients at later stages. Therefore, confounding factors introduced by different shunt types or variable anatomy may influence the analysis. Furthermore, reliable measurements of aortic arch dimension could be performed only on lateral angiograms. A biplanar or even 3-dimensional measurement would add important information to this analysis and give a more complete understanding of the processes reported. The different flow patterns in the neoaorta based on the shunt type are of great interest, but a potential effect could not be assessed due to the low number of Sano shunts pre-Fontan. However, aortic arch reinterventions, ascending aortic dimensions, and peak velocity in the distal aortic arch did not differ among patients with modified BT-shunt and Sano shunt in the single-ventricle reconstruction trial. ${ }^{26,27}$ If the increase in DA $z$ scores is indeed caused by an increase in lower body perfusion after stage II, this should be more pronounced in patients with a modified BT-shunt than a Sano shunt. As to our knowledge, the low number of patients with the latter in this study's patient population is not an effect of worse outcome. The lower rate of classic HLHS during followup may affect interpretation of ventricular function as well.

\section{CONCLUSIONS}

Aortic arch architecture after aortic arch reconstruction in the Norwood procedure using the interdigitating technique is quite different from that of the normal aorta. The reconstructed aortic arch had a proportional growth pattern with no further geometrical distortion. The interdigitating technique yields low recoarctation and reintervention rate but further reduction in reintervention rate can be achieved by avoiding both deficient and excessive patching. Although the impact of the reconstruction itself may be obscured by a multitude of cofactors, the optimal shape of the neoaortic arch needs to be defined and the best patching material remains to be determined.

\section{Conflict of Interest Statement}

Authors have nothing to disclose with regard to commercial support.

\section{References}

1. Larrazabal LA, Tierney ESS, Brown DW, Gauvreau K, Vida VL, Bergersen L, et al. Ventricular function deteriorates with recurrent coarctation in hypoplastic left heart syndrome. Ann Thorac Surg. 2008;86:869-74.

2. Voges I, Jerosch-Herold M, Hedderich J, Westphal C, Hart C, Helle M, et al. Maladaptive aortic properties in children after palliation of hypoplastic left heart syndrome assessed by cardiovascular magnetic resonance imaging. Circulation. 2010;122:1068-76.

3. Voges I, Jerosch-Herold M, Wegner P, Hart C, Gabbert D, Al Bulushi A, et al. Frequent dilatation of the descending aorta in children with hypoplastic left heart syndrome relates to decreased aortic arch elasticity. J Am Heart Assoc. 2015;4: e002107.

4. Schlangen J, Fischer G, Petko C, Hansen JH, Voges I, Rickers C, et al. Arterial elastance and its impact on intrinsic right ventricular function in palliated hypoplastic left heart syndrome. Int J Cardiol. 2013;168:5385-9.

5. Plummer ST, Hornik CP, Baker H, Fleming GA, Foerster S, Ferguson ME, et al. Maladaptive aortic properties after the Norwood procedure: an angiographic analysis of the Pediatric Heart Network Single Ventricle Reconstruction Trial. J Thorac Cardiovasc Surg. 2016;152:471-9.e3.

6. Fraser CD, Mee RB. Modified Norwood procedure for hypoplastic left heart syndrome. Ann Thorac Surg. 1995;60:S546-9.

7. Ishino K, Stümper O, De Giovanni JJV, Silove ED, Wright JGC, Sethia B, et al. The modified Norwood procedure for hypoplastic left heart syndrome: early to 
intermediate results of 120 patients with particular reference to aortic arch repair. J Thorac Cardiovasc Surg. 1999:117:920-30.

8. Gargiulo G, Napoleone CP, Solinas M, Frascaroli G, Pierangeli A. A new patch for the Norwood procedure. Ann Thorac Surg. 1999;68:1873-4.

9. Vicchio M, Nava A, Caianiello G. Bovine jugular vein as aortic enlargement patch in the Norwood procedure. J Thorac Cardiovasc Surg. 2007;134:819.

10. Healy DG, Nolke L, Wood AE. Bovine jugular vein as a shaped alternative patch material for aortic augmentation in the Norwood procedure. J Thorac Cardiovasc Surg. 2007; 133:567-8

11. Biglino G, Giardini A, Ntsinjana HN, Schievano S, Hsia T-Y, Taylor AM. Ventriculoarterial coupling in palliated hypoplastic left heart syndrome: noninvasive assessment of the effects of surgical arch reconstruction and shunt type. J Thorac Cardiovasc Surg. 2014;148:1526-33.

12. Burkhart HM, Ashburn DA, Konstantinov IE, De Oliveira NC, Benson L, Williams WG, et al. Interdigitating arch reconstruction eliminates recurrent coarctation after the Norwood procedure. J Thorac Cardiovasc Surg. 2005;130:61-5.

13. Lamers LJ, Frommelt PC, Mussatto KA, Jaquiss RDB, Mitchell ME, Tweddell JS. Coarctectomy combined with an interdigitating arch reconstruction results in a lower incidence of recurrent arch obstruction after the Norwood procedure than coarctectomy alone. J Thorac Cardiovasc Surg. 2012;143:1098-102.

14. Teien DE, Wendel H, Björnebrink J, Ekelund L. Evaluation of anatomical obstruction by Doppler echocardiography and magnetic resonance imaging in patients with coarctation of the aorta. Br Heart J. 1993;69:352-5.

15. Tweddell JS, Hoffman GM, Mussatto Ka, Fedderly RT, Berger S, Jaquiss RDB, et al. Improved survival of patients undergoing palliation of hypoplastic left heart syndrome: lessons learned from 115 consecutive patients. Circulation. 2002;106: I82-9.

16. Newburger JW, Sleeper LA, Bellinger DC, Goldberg CS, Tabbutt S, Lu M, et al. Early developmental outcome in children with hypoplastic left heart syndrome and related anomalies: The Single Ventricle Reconstruction Trial. Circulation. 2012;125:2081-91.

17. Oster ME, Ehrlich A, King E, Petit CJ, Clabby M, Smith S, et al. Association of interstage home monitoring with mortality, readmissions, and weight gain: clinical perspective. Circulation. 2015;132:502-8.
18. Morell VO, Wearden PA. Experience with bovine pericardium for the reconstruction of the aortic arch in patients undergoing a Norwood procedure. Ann Thorac Surg. 2007;84:1312-5.

19. Machii M, Becker AE. Nature of coarctation in hypoplastic left heart syndrome Ann Thorac Surg. 1995;59:1491-4.

20. Sivanandam S, Mackey-Bojack SM, Moller JH. Pathology of the aortic arch in hypoplastic left heart syndrome: surgical implications. Pediatr Cardiol. 2011; 32:189-92.

21. Itatani K, Miyaji K, Qian Y, Liu JL, Miyakoshi T, Murakami A, et al. Influence of surgical arch reconstruction methods on single ventricle workload in the Norwood procedure. J Thorac Cardiovasc Surg. 2012;144:130-8.

22. Giardini A, Biglino G, Hsia TY. Letter by Giardini et al regarding article, "Mal adaptive aortic properties in children after palliation of hypoplastic left heart syndrome assessed by cardiovascular magnetic resonance imaging." Circulation 2011;123:e594; author reply e595.

23. Mahle WT, Rychik J, Weinberg PM, Cohen MS. Growth characteristics of the aortic arch after the Norwood operation. J Am Coll Cardiol. 1998;32:1951-4.

24. Hasegawa T, Oshima Y, Maruo A, Matsuhisa H, Tanaka A, Noda R, et al. Aortic arch geometry after the Norwood procedure: the value of arch angle augmentation. J Thorac Cardiovasc Surg. 2015;150:358-66.

25. Ferns SJ, El Zein C, Maruboyina SP, Subramanian S, Van Bergen AH, Ilbawi MN. Improved results of aortic arch reconstruction in the Norwood procedure. Ann Thorac Surg. 2016;102:178-85.

26. Newburger JW, Sleeper LA, Frommelt PC, Pearson GD, Mahle WT, Chen S, et al. Transplantation-free survival and interventions at 3 years in the single ventricle reconstruction trial. Circulation. 2014;129:2013-20.

27. Frommelt PC, Gerstenberger E, Cnota JF, Cohen MS, Gorentz J, Hill KD, et al Impact of initial shunt type on cardiac size and function in children with single right ventricle anomalies before the Fontan procedure: the single ventricle reconstruction extension trial. J Am Coll Cardiol. 2014:64:2026-35.

Key Words: cardiovascular surgery, congenital heart disease, aortic arch, hypoplastic left heart syndrome

Readers who found these articles interesting may also like to read the following papers found in recent and future issues of our sister publications, Seminars in Thoracic and Cardiovascular Surgery and Operative Techniques in Thoracic and Cardiovascular Surgery!

\section{Congenital: Hypoplastic Left Heart Syndrome}

Biventricular Repair With a Ross Procedure After a Norwood Procedure: A Big Operation for a Big Problem. Kirk R. Kanter. Semin Thoracic Surg 2016:90-91.

Validation of a Simple Score to Determine Risk of Hospital Mortality After the Norwood Procedure. Shahryar M. Chowdhury. Semin Thoracic Surg 2016:425-433.

The Pearls and Perils of Settling Scores in Public. Edward Buratto. Semin Thoracic Surg 2016:434-435.

Unanticipated Readmissions During the Interstage Period in Patients with Hypoplastic Left Heart Syndrome: Can the Numbers be Safely Reduced? Sarah Tabbutt. Semin Thoracic Surg 2016:In press.

Intracoronary Stem Cell Delivery To The Right Ventricle: A Preclinical Study. Brody Wehman. Semin Thoracic Surg 2016:In press. 


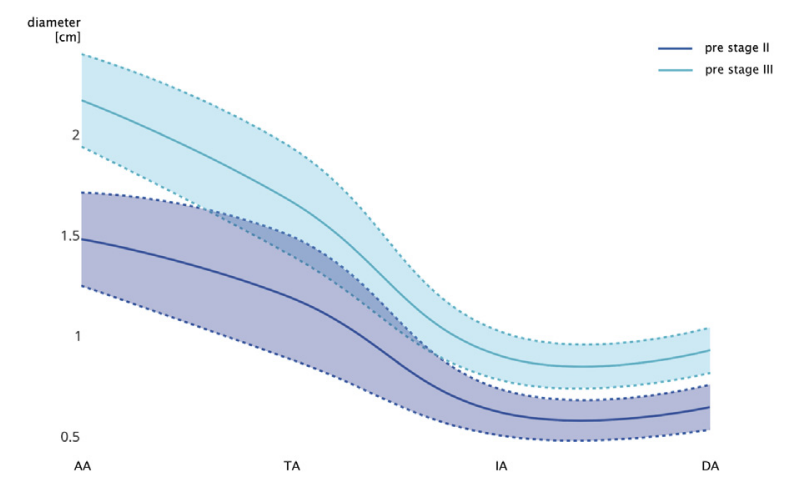

FIGURE E1. Changes in mean aortic diameter from proximal to distal. Although not based on continuous measurements, the plot depicts a relatively sudden tapering between the transverse arch and the interdigitating anastomosis, which persists on pre-stage III measurements. Shaded area between dotted lines depicts \pm 1 standard deviation. $A A$, ascending aorta; $D A$, descending aorta; $I A$, interdigitating anastomosis; $T A$, transverse arch. 